\title{
Quantitative Determination of Naphthalenes in Tobacco Smoke by Gas Chromatography*
}

\author{
by R. F. Arrendale, R. F. Severson and M. E. Snook
}

Tobacco and Health Laboratory, Science and Education Administration / Agricultural Research, United States Department of Agriculture, Athens, Georgia, U.S.A.

\section{INTRODUCTION}

In previous papers from this laboratory, analytical methods were presented for the isolation and identification of the complex mixture of polynuclear aromatic hydrocarbons $(\mathrm{PAH})$ in cigarette smoke $(1-6)$. During that work, we developed a method for the quantitative analysis of three-ring and larger PAH in small quantities of cigarette smoke condensate (CSC) (Figure 1) $(2,5)$. The final gel adsorption chromatographic step not only isolated the PAH but also separated the multialkylated PAH from the monomethyl and parent PAH (GF-B and GF-C, respectively, Figure 2) (7).

Dividing the complex smoke PAH fraction into two cuts allowed the quantitation of the major parent $\mathrm{PAH}$ isolated in GF-C (Figure 3). Recovery studies with ${ }^{14} \mathrm{C}$ benzo[a]pyrene $(\mathrm{BaP})$ and ${ }^{14} \mathrm{C}$-anthracene indicated quantitative recovery of these smoke PAH (5). However, our work and that of others indicated that the levels of naphthalenes and fluorenes in the chromatograms (Figure

Figure 1. Four-step polynuclear aromatic hydrocarbon (PAH) Isolation scheme for small quantitles of clgarette

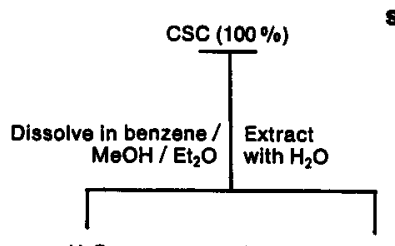

$\mathrm{H}_{2} \mathrm{O}$

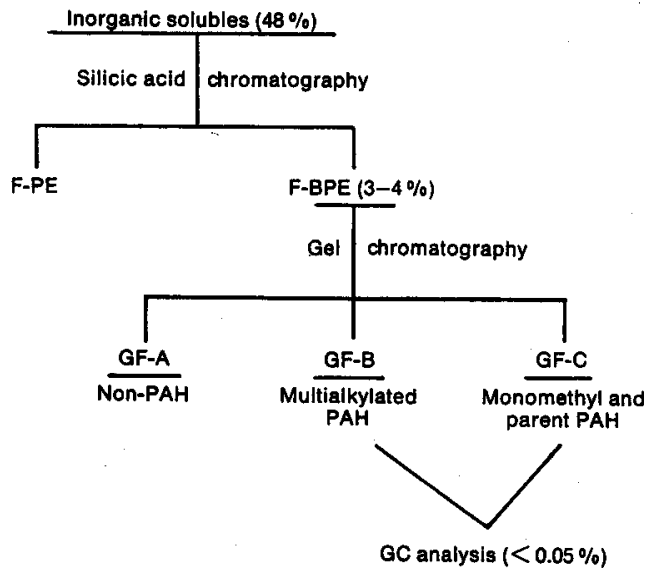

* Received: 1st August 1979 - accepted: 3rd January 1980.

+ Reference to a company or product name does not imply approval or recommendation by the United States Department of Agriculture.
3) were less than the actual levels present in $\operatorname{CsC}(2,8,9$, 10). The high volatility of the naphthalenes suggested their loss during solvent reduction (9). It became apparent that special solvent removal techniques must be developed for quantitative isolation of these compounds. We now describe our modification of the four-step PAH isolation scheme such that all the major PAH from naphthalene to coronene, including their methyl derivatives, can be quantitatively isolated.

\section{EXPERIMENTAL}

\section{Cigarette Smoke Condensate Collection}

University of Kentucky reference cigarettes (type 1R1, $85 \mathrm{~mm}$ non-filter) were conditioned at $60 \%$ relative humidity for 48 hours and were smoked to a $30 \mathrm{~mm}$ butt length on a 30-port Borgwaldt ${ }^{+}$smoking machine under the standard smoking conditions of $1 \mathrm{puff} / \mathrm{min}, 2$-second puff duration, and a puff volume of $35 \mathrm{ml}(11,12)$. The condensate was collected in two dry-ice traps with a glass wool plug in the last trap.

\section{Chromatography}

Silicic acid (SA) and gel chromatography were performed as before (5), but a $30 \mathrm{ml}$ injection loop was used.

\section{Gas Chromatographic Standards}

Except for 2-methylnaphthalene, the PAH standards used for determination of gas dromatographic (GC) response data were purified by chromatography on a short SA column with benzene/ petroleum ether (B/PE, 1/3, v/v) followed by recrystallization. The 2-methylnaphthalene was used as obtained from Eastman Kodak Co.

\section{Gas Chromatography}

GC analyses were performed with a Hewlett-Padkard -model 5840A gas chromatograph equipped with a $15 \mathrm{ft}$. $X$ $1 / 8$ in. stainless steel column, packed with $5 \%$ Dexsil $300 \mathrm{GC}$ on $100 / 120$ mesh Chromosorb W-AW. For Figure 3 , the temperature program was $90^{\circ} \mathrm{C}$ for $10 \mathrm{~min}, 90$ $325^{\circ} \mathrm{C}$ at $2 \% \mathrm{~min}$, and held at $325^{\circ} \mathrm{C}$ for $45 \mathrm{~min}$. For the chromatogram shown in Figure 4, the temperature program was $70-250^{\circ} \mathrm{C}$ at $2 \% \mathrm{~min}$. Helium flow was $40 \mathrm{ml} /$ min at $90^{\circ} \mathrm{C}$; injector temperature, $290^{\circ} \mathrm{C}$; flame ionization detector temperature, $350^{\circ} \mathrm{C}$. 


\section{Isolation Procedure}

Cigarettes (270) were machine smoked and materials adhering to the glass connecting tubes in the trapping system were dissolved alternately with methanol and benzene into the traps. After warming to room temperature, the CSC solutions in the traps were quantitatively transferred into a separatory funnel with alternating portions of benzene, methanol, and ethyl ether (total volumes 200, 100, $100 \mathrm{ml}$, respectively). The organic solution was washed with glass-distilled water $(3 \times 200 \mathrm{ml})$, and the aqueous portion was cross-extracted with 1:1 benzene / ethyl ether $(3 \times 50 \mathrm{ml})$. The organic layers were combined and transferred to a 2-liter round-bottom flask. Isooctane (IO, $200 \mathrm{ml}$ ) was added, and the flask was placed on a modified commercial distillation apparatus (MCDA) developed by Schepartz et al. (13) at our laboratory. The volume was reduced until most of the benzene had been removed (final volume about $2.0 \mathrm{ml}$ ). After the addition of $40 \mathrm{~g}$ of silicic acid (SA), the remaining solvent was removed on a rotary evaporator $\left(40^{\circ} \mathrm{C}\right)$ until a semi-solid mixture of $\mathrm{IO}, \mathrm{SA}$, and sample remained. This residue was slurried with $150 \mathrm{ml}$ of petroleum ether (PE) and added to the top of a $100 \mathrm{~g} \mathrm{SA}$ column. The column was eluted with $400 \mathrm{ml}$ $\mathrm{PE}$ to yield fraction F-PE. (This fraction should be colorless. The elution of colored material means that the SA was not sufficiently active to retain the low molecular weight PAH.) The round-bottom flask was rinsed with $100 \mathrm{ml}$ of $\mathrm{B} / \mathrm{PE}(1: 3, \mathrm{v} / \mathrm{v})$, and the rinsings were added to the column. The column was eluted with $900 \mathrm{ml}$ of the $\mathrm{B} / \mathrm{PE}$ solvent mixture to yield fraction F-BPE, which was collected directly into a $2000 \mathrm{ml}$ round-bottom flask. Several boiling stones were added (high purity, amphoteric Alundum granules), and the volume was reduced to about $25 \mathrm{ml}$ with MCDA. The residue was quantitatively transferred to a $50 \mathrm{ml}$ pear-shaped flask. A small magnetic stirring bar was added for agitation and the flask was connected to a Kontes' Bantum-ware vacuum-jadketed Vigreaux distillation head. The flask was heated with a heating mantle and the temperature of the distillation was monitored with an immersion thermometer at the top of the Vigreaux column. Sample volume was reduced to about $3 \mathrm{ml}$ and the residue was quantitatively transferred with benzene to a $5 \mathrm{ml}$ volumetric flask. A $3 \mathrm{ml}$ sample of

Figure 2. Absorbance curves for traction F-BPE and for PAH standards used to define limits for gel chromatography fractlon cuts (8). (GF-A contalned non-PAH material).

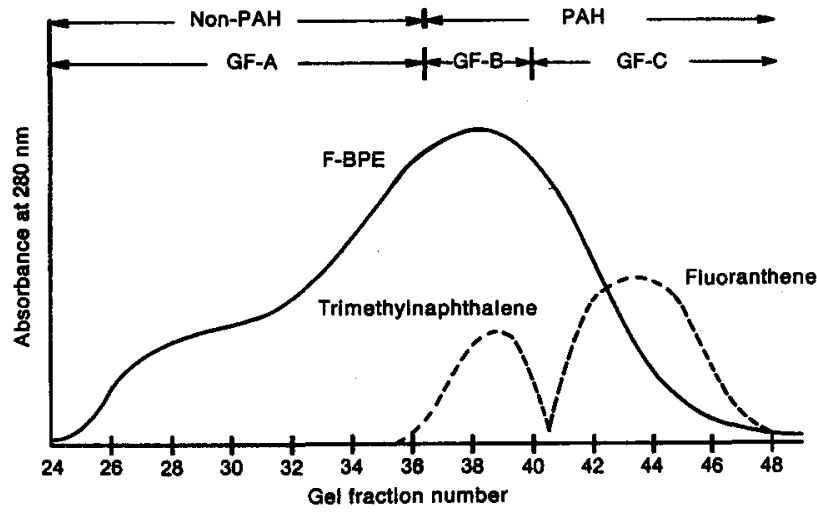

the F-BPE solution was injected onto the gel system, and sixty $8 \mathrm{ml}$ fractions were collected. Gel fractions 35-60 (Figure 2) were combined into a $2000 \mathrm{ml}$ round-bottom flask to yield the PAH isolate. The volume was reduced to about $25 \mathrm{ml}$ with the MCDA, as above, and the residue (PAH isolate) was quantitatively transferred to a $50 \mathrm{ml}$ pear-shaped flask. Pentatriacontane $\left(C_{35}\right)$ was added as internal standard, and the volume was reduced by distillation with a Vigreaux column to $3 \mathrm{ml}$ as above. At this point, concentration of the $C_{35}$ internal standard should be about $0.5 \mu \mathrm{g} / \mu \mathrm{l}$. Three to eight microliters of the PAH solution were used for GC analysis.

\section{RESULTS AND DISCUSSION}

Major losses of volatile, small-ring PAH occurred in our previous method during conventional solvent reduction (rotary evaporation and nitrogen blow-down) to volumes suitable for gel and gas chromatography. Even with solvent removal by efficient distillation columns, considerable losses of ${ }^{14} \mathrm{C}$-naphthalene occurred, when solutions were reduced below $2.5 \mathrm{ml}$ (Table 1). Therefore, this was

Table 1. Recovery of ${ }^{14} \mathrm{C}$-naphthalene after solvent reduction.

\begin{tabular}{cc}
\hline Volume reduction * & $\begin{array}{c}\text { Recovery of } \\
\text { 14C-naphthalene (\%) }\end{array}$ \\
\hline $1000 \mathrm{ml}$ to $2.5 \mathrm{ml}$ & 99.2 \\
$1000 \mathrm{ml}$ to $1.0 \mathrm{ml}$ & 87.3 \\
$250 \mathrm{ml}$ to $2.0 \mathrm{ml}$ & 96.0 \\
$250 \mathrm{ml}$ to $0.5 \mathrm{ml}$ & 65.0 \\
\hline
\end{tabular}

* Volumes were reduced with the modifled commercial distillation apparatus (MCDA) and a vacuum-jacketed Vlgreaux distillation head.

set as the lowest level for solvent reduction. At a final volume of $2.5 \mathrm{ml}$, the small-ring PAH could still be readily analyzed in CSC obtained from 200 cigarettes.

The recovery of naphthalene from CSC was verified with ${ }^{14} \mathrm{C}$-naphthalene at each step in the procedure, including the solvent reduction step (Table 2). Quantitative recovery was achieved in the water extraction, the SA column chromatography, and the gel filtration steps; and it was also quantitative for the solvent-reduction steps. Total naphthalene recovery of $91 \%$ (Table 2) for the entire fractionation scheme was acceptable. When counting at each step in the process, lower recoveries could result from

Table 2. Recovery of ${ }^{14} \mathrm{C}$-naphthalene (average of two analyses).

\begin{tabular}{lcc}
\hline $\begin{array}{l}\text { Steps in } \\
\text { PAH isolation }\end{array}$ & $\begin{array}{c}\text { Recovery/step } \\
(\%)\end{array}$ & $\begin{array}{c}\text { Recovery } \\
(\%)\end{array}$ \\
\hline $\begin{array}{l}\text { Cigarette smoke } \\
\text { condensate }\end{array}$ & 100 & 100 \\
\hline Organic solubles & 99 & 99 \\
\hline $\begin{array}{l}\text { Silicic acid } \\
\text { Solvent reduction } \\
\text { (to 2.5 ml) }\end{array}$ & 99 & 98 \\
\hline $\begin{array}{l}\text { Gel filtration } \\
\text { Solvent reduction } \\
\text { (to 2.5 ml) }\end{array}$ & 96 & 95 \\
\hline
\end{tabular}


Figure 3. Gas chromatograms from a previous analysis of PAH from reference clgarettes $(2,5)$.
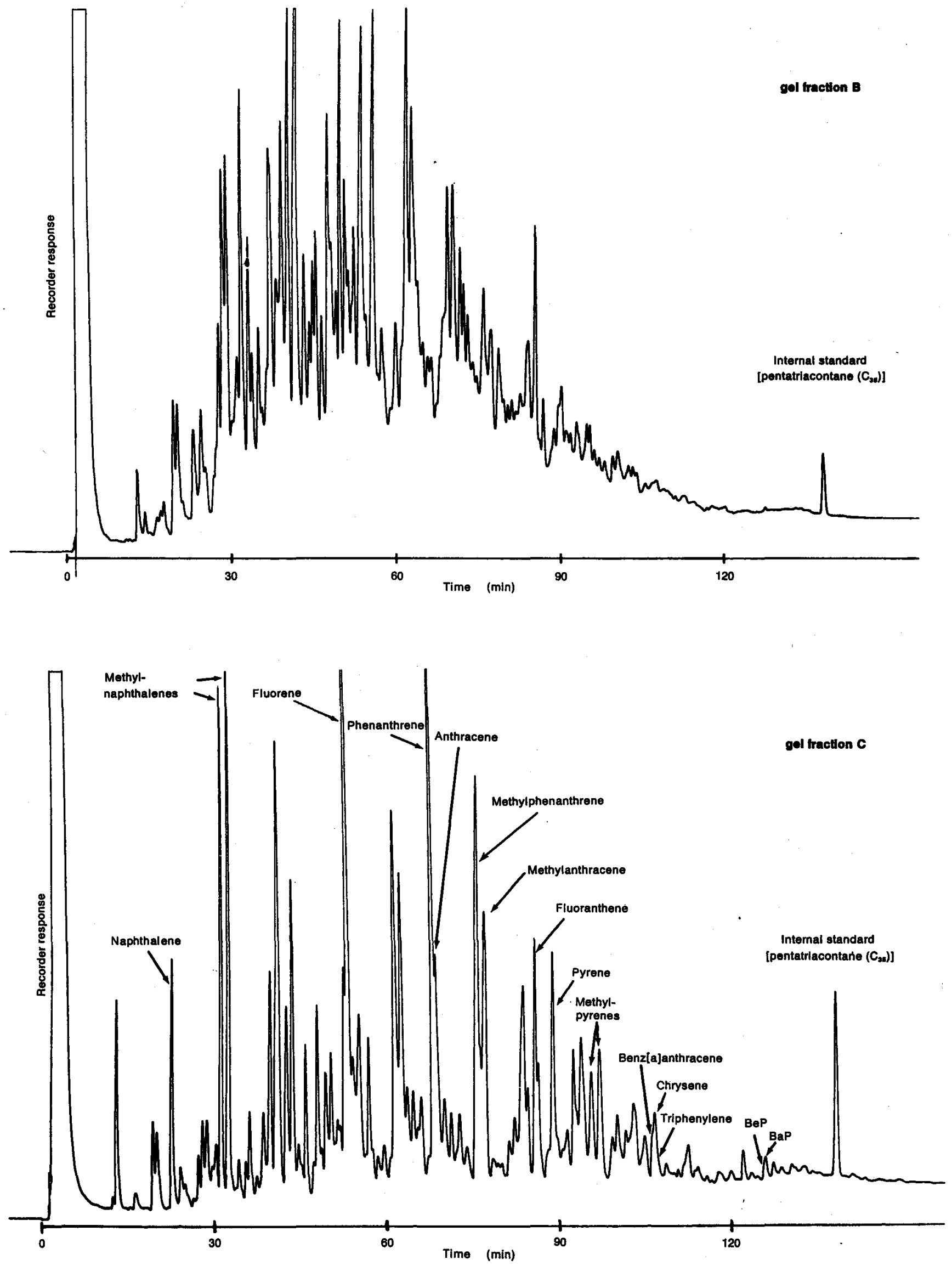
Table 3. Major components Identifled In "volatlle PAH" isolate.

1. Indene

2. Dimethylstyrenes, methylbenzo[b]furans

3, 4. Methylindenes

5. Naphthalene

6. Dimethylbenzo[b]furans

7. Dimethylindenes, ethylindenes, ethyldimethylIndenes

8. 2-Methylnaphthalene

9. 1-Methylnaphthalene

8-13. Trimethylindenes, trimethylbenzo[b]furans

12. Tetramethylbenzo[b]furans

13. Biphenyl, tetramethylbenzo[b]furans, tetramethylindenes

14. Tetramethylbenzo[b]furans, tetramethylindenes

15. 1- \& 2-Ethylnaphthalene, tetramethylbenzo[b]furans, tetramethylindenes

16. 2,6- \& 2,7-Dimethylnaphthalene, 1-vinylnaphthalene

17. 1,3-, 1,7- \& 1,6-Dimethylnaphthalene, 2-vinylnaphthalene

18. 2,3-, 1,4- \& 1,5-Dimethylnaphthalene, isopropylnaphthalene

19. Acenaphthylene, 1,2-dimethylnaphthalene

20. 3-Methylbiphenyl

21. 4-Methylbiphenyl

22. Acenaphthene, 1,8-dimethylnaphthalene, bibenzyl

23. Ethylmethylnaphthalenes, trimethylnaphthalenes

24. Dibenzofurans, trimethylnaphthalenes

25, 26. Trimethyinaphthalenes

27. Tri \& tetramethylnaphthalenes

28. Trimethylnaphthalenes

29. Trlmethylnaphthalenes, methylacenaphthylene
Table 3 (contd.)

30. Methylacenaphthylenes

31. Fluorene

32. Methylacenaphthylenes, 9-methylfluorene

33. 1-Methyldibenzofuran, tetramethylnaphthalenes

34. 2- \& 4-Methyldibenzofuran, tetramethylnaphthalenes

35, 36. Dimethylacenaphthalenes, tetra \& pentamethylnaphthalenes

37. Trimethylacenaphthalenes, pentamethylnaphthalenes

38. 2- \& 3-Methylfluorene, dimethylacenaphthylenes, pentamethylnaphthalenes

39. 1- \& 4-Methylfluorene, dimethylacenaphthylenes

40-42. Trimethylacenaphthylenes, dimethylacenaphthylenes, dimethylbenzofurans

losses during the many transfers of material. Thus, when determined only at the point of GC analysis, recoveries were about $95 \%$.

The use of radio-labeled compounds, such as ${ }^{14} \mathrm{C}$-naphthalene and ${ }^{14} \mathrm{C}$-phenanthrene, as internal standards in isolation schemes for the naphthalenes has been advocated (9). However, the use of our modified four-step isolation procedure would assure quantitative $\mathrm{PAH}$ recovery and reproducibility and would avoid the inconvenient use of radio-labeled tracers.

The GC profile of the volatile, small-ring PAH from Kentudky 1R1 cigarettes isolated by our modified method is shown in Figure 4. The major volatile components are listed in Table 3. The chromatogram represents about half of the total PAH profile given in Figure 3. Note the high levels of alkylated benzenes (toluene, xylenes, etc.) and styrenes eluting before indene (Peak 1 in Figure 4). In contrast, the majority of these volatile $\mathrm{PAH}$ are absent in the GC profiles (Figure 3 ) of gel fractions obtained by our previous isolation method. A complete identification of the components of GF-B and GF-C has been reported $(1,4$, 6).

Figure 4. Gas chromatogram of "volatile PAH" isolate derlved from smoke condensate of reference cigarettes.

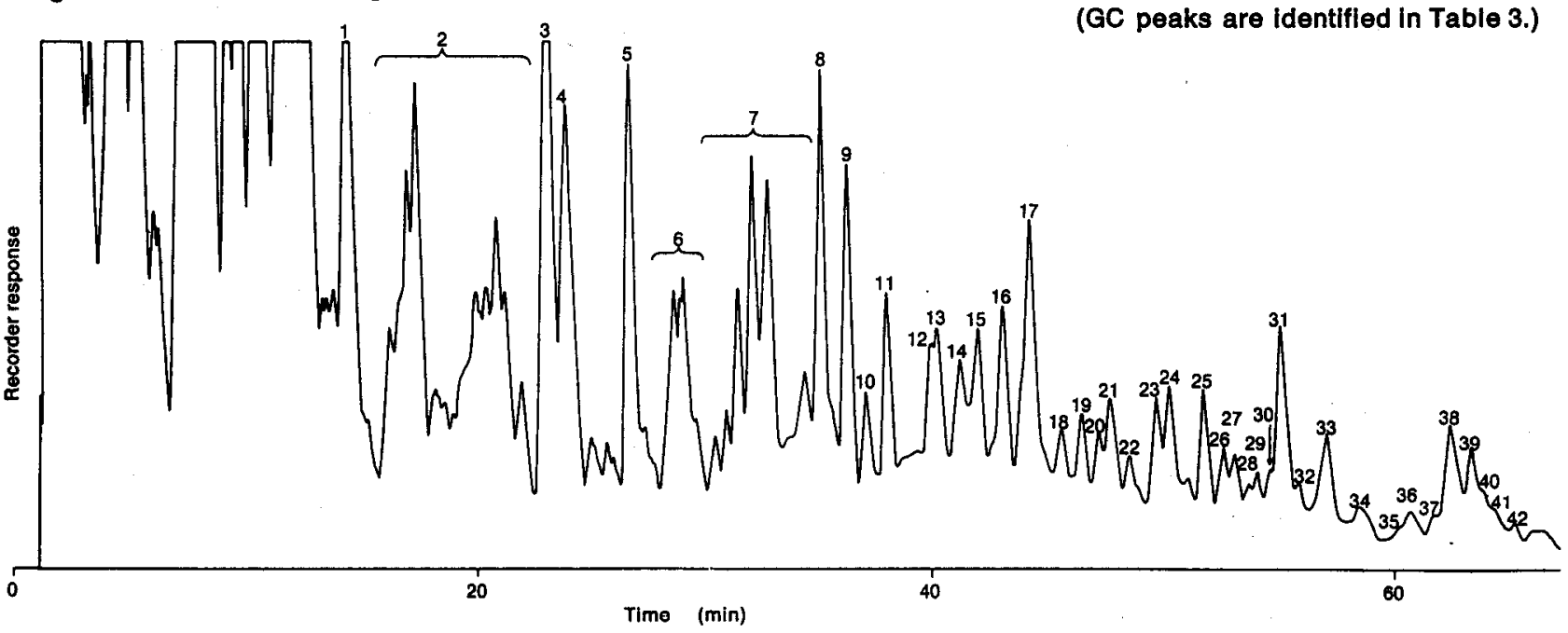


Table 4. Selected PAH levels in clgarette smoke condensate from 1R1 clgarettes smoked to a $30 \mathrm{~mm}$ butt length.

\begin{tabular}{lc}
\hline Polycyclic aromatic hydrocarbons & $\begin{array}{c}\text { amount } \\
\text { (ng/cigarette) }\end{array}$ \\
\hline Naphthalene & 2560.0 \\
2-Methylnaphthalene & 2490.0 \\
1-Methylnaphthalene & 1930.0 \\
Fluorene & 1640.0 \\
Phenanthrene + anthracene & $440.0(5)$ \\
Methylphenanthrene + methylanthracene & $1020.0(5)$ \\
Fluoranthene & $148.0(5)$ \\
Pyrene & $139.0(5)$ \\
Methylpyrene & $199.0(5)$ \\
Benz[a]anthracene + chrysene + & $86.0(5)$ \\
triphenylene & $25.0(5)$ \\
Benzo[a]pyrene + benzo[e]pyrene & $3.0(3)$ \\
Perylene & $6.0(3)$ \\
Indenopyrene & $5.0(3)$ \\
Benzo[ghi]perylene & $3.0(3)$ \\
Anthanthrene & $5.0(3)$ \\
Methylbenzo[ghi]perylene & $1.0(3)$ \\
Coronene &
\end{tabular}

The levels of selected PAH in smoke condensate from Kentudky 1R1 reference cigarettes are listed in Table 4. These data were obtained based upon peak areas of sample components versus peak area of our internal standard $\left(\mathrm{C}_{35}\right)$, taking into consideration the relative responses of each component. The quantitative data on naphthalene to fluorene in Table 4 is the average of two complete analyses. The average relative percent standard deviation for these two analyses was $5.1 \%$. Values are given for $\mathrm{PAH}$ in $\mathrm{ng} /$ cigarette over the total PAH range from naphthalene to coronene. Our value of $2.5 \mu \mathrm{g} /$ cigarette for naphthalene for a Kentucky 1R1 cigarette smoked to a $35 \mathrm{~mm}$ butt length is in good agreement with $2.76 \mu \mathrm{g} /$ cigarette found by Schmeltz et al. (9) when smoking to a $23 \mathrm{~mm}$ butt length. However, their levels of alkylated $\mathrm{PAH}$ were lower. They obtained a value of $2.22 \mu \mathrm{g} / \mathrm{ciga}-$ rette for the combined amounts of 1-methyl and 2-methylnaphthalenes, as compared with our value of $4.42 \mu \mathrm{g} / \mathrm{ciga-}$ rette. We believe that this difference is due to the fact that certain $\mathrm{PAH}$, especially alkylated $\mathrm{PAH}$, have unfavorable partition coefficients in organic solvent-solvent partition systems (14). Our value of $1640 \mathrm{ng} /$ cigarette for fluorene is also much higher than the $782 \mathrm{ng} /$ cigarette obtained by Hoffmann et al. (15) using a less rigorous isolation procedure.

The entire range of PAH from naphthalene to coronene can now be quantitatively isolated by this modified fourstep procedure. This solvent reduction procedure may also be adapted for the quantitative isolation of other volatile compounds from CSC, while the total methodology should be most applicable to the analysis of environmental samples containing volatile and non-volatile compounds, such as PAH.

\section{SUMMARY}

Our previously developed method for the determination of three-ring and larger polynuclear aromatic hydrocarbons (PAH) of cigarette smoke was modified to allow quantitative determination of the more volatile PAH. Recovery tests with ${ }^{14} \mathrm{C}$-naphthalene showed that this smoke PAH was being lost to a large extent during the usual solvent evaporation steps. Special solvent removal techniques, using very efficient distillation equipment, were developed and tested to quantitatively recover the naphthalenes. The gas chromatographic profile for the volatile $\mathrm{PAH}$, including naphthalenes, fluorenes, and related compounds, is discussed in relation to the modified procedure. Quantitative values for some of the PAH of cigarette smoke are given. The developed solvent removal and concentration techniques should be most applicable to the analysis of environmental samples containing volatile compounds.

\section{ZUSAMMENFASSUNG}

Das von den Autoren früher entwickelte Verfahren zur Bestimmung der polycyclischen aromatischen Kohlenwasserstoffe (PAH) mit drei und mehr Ringen im Cigarettenrauch wurde für den quantitativen Nachweis der flüchtigeren polycyclischen aromatischen Kohlenwasserstoffe modifiziert. Bei Rückgewinnungsversuchen mit ${ }^{14} \mathrm{C}-\mathrm{Naphthalin}$ hatte sich gezeigt, daß dieser Rauchinhaltsstoff während der üblichen Lösungsmittelverdampfung weitgehend verlorengeht. Für die Abtrennung der Lösungsmittel wurden unter Benutzung sehr leistungsstarker Destillationsvorrichtungen besondere Techniken entwickelt und an der quantitativen Wiederauffindung der Naphthaline erprobt. Das gaschromatographische Profil der flüchtigen polycyclischen aromatischen Kohlenwasserstoffe, einschließlich der Naphthaline, Fluorene und verwandter Verbindungen, wird im Zusammenhang mit dem modifizierten Verfahren diskutiert. Für einige der polycyclischen aromatischen Kohlenwasserstoffe des Cigarettenrauches werden quantitative Ergebnisse mitgeteilt. Die beschriebenen Abtrennungs- und Konzentrationsverfahren könnten sich bei der Bestimmung der Luftverunreinigung sehr gut zur Untersuchung von Proben der Umgebungsluft auf flüchtige Verbindungen eignen.

\section{RESUME}

La méthode présentée précédemment pour la détermination des hydrocarbures aromatiques polycycliques (PAH) à trois cycles et plus dans la fumée de cigarette a été modifiée pour la détermination quantitative des $\mathrm{PAH}$ plus volatils. Des essais de récupération au moyen de ${ }^{14} \mathrm{C}$-naphtaline avaient démontré que ce constituant de la fumée disparaît dans une large mesure pendant l'évaporation des solvants. Une technique de distillation tres efficace a été mise au point pour l'élimination des solvants, et éprouvée par la récupération quantitative de la naphtaline. Le chromatogramme en phase gazeuse des PAH vola- 
tils, comprenant des naphtalines, fluorènes et composés apparentés, est discuté par rapport à la méthode modifiée. Des résultats quantitatifs sont communiqués pour certains PAH de la fumée de cigarette. Les techniques décrites pour l'élimination et la concentration des solvants s'appliquent aisement à l'analyse d'echantillons d'air ambiant contenant des composants volatils.

\section{REFERENCES}

1. Snook, M. E., R. F. Severson, H. C. Higman, R. F. Arrendale and $O$. T. Chortyk: Polynuclear aromatic hydrocarbons of tobaccosmoke: Isolation and identification; Beitr. Tabakforsch. 8 (1976) 250-272.

2. Severson, R. F., M. E. Snook, O. T. Chortyk and R. F. Arrendale: A chromatographic analysis for polynuclear aromatic hydrocarbons in small quantities of cigarette smoke condensate; Beitr. Tabakforsch. 8 (1976) 273-282.

3. Severson, R. F., M. E. Snook, H. C. Higman, O. T. Chortyk and F. J. Akin: Isolation, identification and quantitation of the polynuclear aromatic hydrocarbons in tobacco smoke; in: Carcinogenesis, a comprehensive survey, Vol. 1: Polynuclear aromatic hydrocarbons, edited by $R$. Freudenthal and P. W. Jones, Raven Press, New York, N. Y., 1976, pp. 253-270.

4. Snook, M. E., R. F. Severson, R. F. Arrendale, H. C. Higman and $O$. T. Chortyk: The identification of high molecular weight polynuclear aromatic hydrocarbons in a biologically active fraction of cigarette smoke condensate; Beitr. Tabakforsh. 9 (1977) 79_ 101.

5. Severson, R. F., M. E. Snook, R. F. Arrendale and $O$. T. Chortyk: Gas dhromatographic quantitation of polynuclear aromatic hydrocarbons in tobacco smoke; Anal. Chem. 48 (1976) 1866-1872.

6. Snook, M. E., R. F. Severson, R. F. Arrendale, H. C. Higman and O. T. Chortyk: Multi-alkylated polynuclear aromatic hydrocarbons of tobacco smoke: Separation and identification; Beit (1978) 222-247.

7. Snook, M. E.: Gel filtration of methyl-substituted polynuclear aromatic hydrocarbons; Anal. Chim. Acta 81 (1976) 423-427.

8. Severson, R. F., W. S. Schlotzhauer, R. F. Arrendale and M. E. Snook: Correlation of polynuclear aromatic hydrocarbon formation between pyrolysis and smoking; Beitr. 'Tabakforsch. 9 (1977) 23-27.

9. Schmeltz, I., J. Tosk and D. Hoffmann: Formation and determination of naphthalenes in cigarette smoke; Anal. Chem. 48 (1976) 645-650.

10. Severson, R. F., M. E. Snook, F. J. Akin and O. T. Chortyk: Correlation of biological activity with polynuclear aromatic hydrocarbon content of tobacco smoke fractions; in: Carcinogenesis, Vol. 3, Polynuclear aromatic hydrocarbons, edited by $P$. W. Jones and R.I. Freudenthal, Raven Press, New York, N. Y., 1978, pp. 115-130.

11. Pillsbury, H. C., C. C. Bright, K. J. O'Connor and F. W. Irish: Tar and nicotine in cigarette smoke; J. A. O. A. C. 52 (1969) $458-462$.

12. Rothwell, K., ed.: Smoking and collection of condensate; Standard Methods for the Analysis of Tobacco Smoke, Section 2, Tobacco Research Council, London, 1972.

13. Schepartz, A. I., J. J. Ellington and R. F. Severson: A modified commercial distillation apparatus for purification of solvents; Amer. Lab. October 1976, 77-78.

14. Howard, J. W., and E. O. Haenni: The extraction and determination of polynuclear hydrocarbons in paraffin waxes; J. Assoc. Off. Agric. Chem. 46 (1963) 933-941.

15. Hoffmann, D., and G. Rathkamp: Quantitative determination of fluorenes in cigarette smoke and their formation by pyrosynthesis; Anal. Chem. 44 (1972) 899-905.

Authors' address:

Tobacco and Health Laboratory,

Science and Education Administration, Agricultural Research,

S. Department of Agriculture,

P.O. Box 5677,

Athens, Georgia, 30604, U.S.A.

\section{Erratum}

Page 100, Figure 1:

The fourth line of Figure 1 on page 100 should read "organic solubles (48\%)". 